\title{
A Slip-Force Device for Maintaining Constant Lateral Pressure on Retaining Structures in Expansive Soils
}

\author{
Yi Wu \\ Department of Civil Engineering, Guangdong Polytechnic of Water Resources and Electric Engineering, Guangzhou, China \\ Email: 125372329@qq.com
}

How to cite this paper: $\mathrm{Wu}, \mathrm{Y} .(2021) \mathrm{A}$ Slip-Force Device for Maintaining Constant Lateral Pressure on Retaining Structures in Expansive Soils. Open Journal of Civil Engineering, 11, 342-357.

https://doi.org/10.4236/ojce.2021.113020

Received: August 7, 2021

Accepted: September 15, 2021

Published: September 18, 2021

Copyright $\odot 2021$ by author(s) and Scientific Research Publishing Inc. This work is licensed under the Creative Commons Attribution International License (CC BY 4.0).

http://creativecommons.org/licenses/by/4.0/

\begin{abstract}
Expansive soils can pose tough issues to civil engineering applications. In a typical year, expansive soils can cause a greater financial loss than earthquakes, floods, hurricanes and tornadoes combined. Various means have been studied to tackle problems associated with expansive soils. The majority of the methods are based on treatment of the soils. While the methods may be effective in some cases, their limitations are also obvious: The treatment normally involves complex processes and may not be eco-friendly in the long run. In many cases, the effectiveness of the treatment is uncertain. A retaining system that maintains a constant lateral pressure is proposed, which consists of three components: the retaining sheet, the slip-force device and the bracing column. The retaining sheet bears the pressure exerted by expansive backfills and is not embedded into the soils. Placed between the retaining sheet and bracing column, the slip-force device permits displacement of the retaining sheet but keeps the force on the sheet and the bracing column constant. The governing equation of the motion of the piston in the slip-force device is derived and a numerical simulation of a practical case is conducted based on the derived governing equation. Numerical results show that as the expansive soil swell, the spring force will increase and the piston will move accordingly. When the pressure of the oil in chamber reaches the open threshold of the unidirectional relief valve, the valve will open and the spring force and the oil pressure in the chamber will keep constant. The results also show that some parameters, such as damping ratio, have very slight influences on the device behavior, say $2 \times 10^{-6}$ or even $4.8 \times 10^{-9}$. Theoretical and numerical studies prove the effectiveness of the proposed retaining system.
\end{abstract}

\section{Keywords}

Expansive Soils, Retaining Structures, Slip-Force Device, Swell, Shrink, Bracing 


\section{Introduction}

An expansive or reactive soil is any soil that responds to changes in soil moisture content in a fairly obvious manner [1]. The expansive soil contains primarily clay, the expansive properties of which are normally due to the active clay minerals, such as montmorillonite, combination of montmorillonite and other clay minerals, etc. While not considered active, Kaolinites and illites may contribute to expansive properties if sufficient amounts are present in the material [2].

Swelling and shrinkage are two major problems caused by expansive soils when there are appreciable amounts of changes in water. Such problems can lead to differential settlement, creep and heaving. The detrimental effect of swelling and shrinkage is more significant for lightly loaded structures, including pavements, railways, roadways, foundations and channel or reservoir linings [3] [4]. Swelling pressure can accumulate if there is no mechanism, e.g., cracking, to release it and consequently exert additional unwanted load on the main structures. Swelling will decrease the bearing capacities and shearing strength in saturated clay [5]. For cut, excavated or difficultly workable soil swelling leads to increased susceptibility to erosion. On the other hand, the decreasing of the water content could cause expansive soil to collapse, leading to settlement [6] and cracks [7]. If the swelling and shrinkage procedures repeat on a slope, slope creep will occur [6].

The damage to the retaining structures in expansive soils is mainly caused by large lateral swelling pressures [5] [7] with a magnitude up to twice that of the vertical swelling pressure [8] and sometimes, even an order of magnitude higher [5] [9]. Such large lateral swelling pressures can lead to significant damage and economic losses [10] [11].

There are four major classical approaches to the problems caused by the lateral swelling pressure: 1) replacing the expansive backfill with non-expansive materials [12]; 2) incorporating lime, Portland cement, industrial byproducts or wastes like fly ash into the expansive backfill; 3 ) applying compressible materials like geogrid, geofoam, geotextile, etc., to the backfill and the immediate back of the retaining structure to house the swell of the expansive backfill [11] [13] [14] [15] [16] [17]; 4) keeping moisture stable, which is the most popular treatment in the whole process with various forms [18].

Although every traditional treatment has its own advantages, limitations still exist. For example, 1) replacing the backfill with non-expansive materials could be highly costly in areas where high quality, non-expansive materials, such as granular materials are scarce; it may also introduce additional uncertainties into the retaining wall design [7] [19]; 2) mixing with lime, cement or industrial byproduct or wastes might make the soils more permeable or even worse, such as for the sulfate soils [18]; 3) using compressible materials or stabilizing water content could be uneconomical [20]; and 4) there are potential eco-environmental issues [21]. 
In this paper, a slip-force device featuring a constant lateral pressure is proposed. The concept is inspired by the passive structural control devices that have been successfully applied to protection of buildings and bridges against earthquake and winds [22] [23] [24]. To the best knowledge of the authors, there has been no report of using any such devices for retaining structures.

\section{Key Technologies and Their Solutions}

\subsection{Key Technologies}

This research needs to solve the following two key issues of the expansive soil retaining wall structure:

First, how to ensure that the retaining structure is not damaged when the expansive soil swells with water;

Second, when the expansive soil swelling with water shrinks when it loses water, how does the retaining structure adapt to this shrinkage and deformation, so as to prepare for the next expansion with water.

\subsection{Solutions for the First Key Technical Issue}

For the first key technical problem, there are three solutions:

First, the spring + buckling bar scheme

This solution is to separate the expansive soil retaining sheets from the bracing structural column, and a force transmission device composed of a spring and a buckling bar in series is arranged between the retaining sheets and the bracing structural column, as shown in Figure 1. The spring is used to adapt to the expansion and deformation of the expansive soil absorbing water, and the buckling bar is to prevent the retaining structural column from being damaged when the expansion pressure is too large. When the expansive soil swells with water, the expansive soil will push the retaining sheets to move toward the bracing column. At this moment, the spring will compress and deform with the increase of pressure, and the pressure on the buckling bar will gradually increase. When the pressure on the buckling bar reaches its Euler critical pressure, the buckling bar is buckled and destroyed, and the thrust acting on the bracing column is

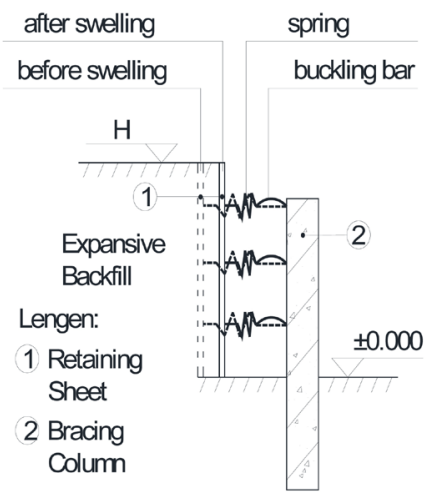

Figure 1. Spring-buckling-bar scheme. 
reduced, thereby protecting the retaining column from damage. When designed according to this scheme, it must be ensured that the Euler critical pressure of the buckling bar is less than the lateral thrust that the cantilever bracing structural column can withstand when it is broken by bending.

The solution of spring + buckling bar actually uses the idea of sacrificing secondary components to protect the main components. This kind of thinking is more common in structural earthquake resistance, as shown in Figure 2, which is the steel column foot joint with wedge device proposed by Japanese scholars represented by Takao Takamatsu [25] [26] [27] [28]. Under the action of strong earthquake lateral load, the anchor bolt on one side of the column foot yields under tension. When the earthquake load subsides, the spring on the column base plate pushes the wedge into the gap between the bolt wedge gasket and the column base plate, and the column base plate drives the column to reset. This device can not only protect the column foot from earthquake damage, but also allow the column to automatically reset after an earthquake.

\section{Second, the oil column pressure scheme}

This scheme is still to separate the expansive soil retaining sheets from the bracing structural column, and a force transmission device consisting of a horizontal cylinder, oil, piston, and vertical oil pipe is set between the retaining sheets and the bracing structural column, as shown in Figure 3. The piston is

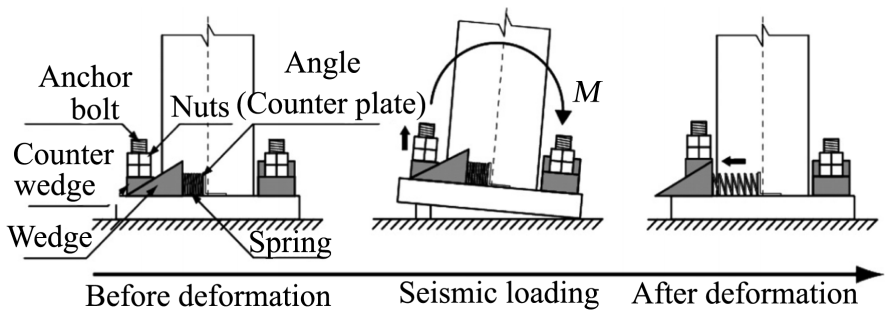

Figure 2. The seismic work process of the column foot with the wedge device.

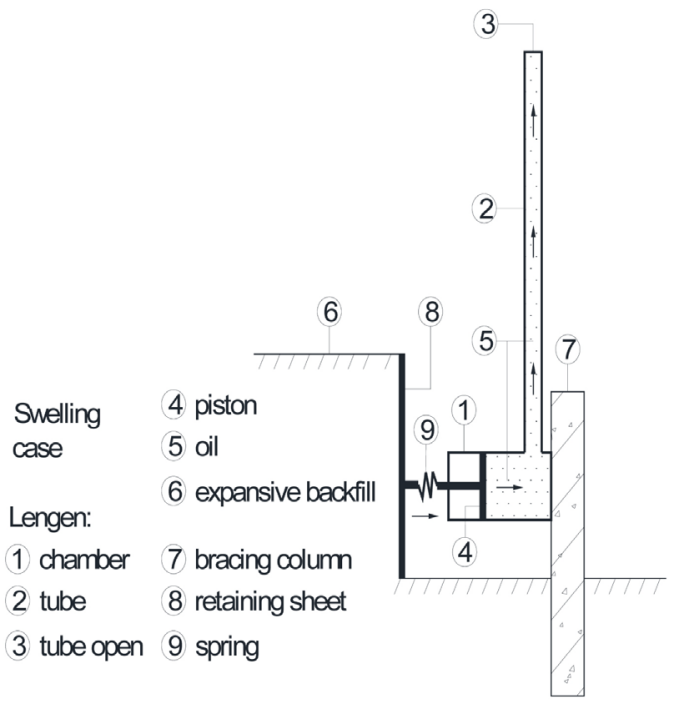

Figure 3. Oil column pressure scheme. 
used to adapt to the deformation of the expansive soil when it absorbs water. The vertical oil pipe has a certain height and the top is open. The vertical oil pipe requires a certain height in order to form a certain pressure in the oil cylinder and give a certain supporting force to the expansive soil retaining sheets. The opening at the top of the vertical oil pipe is to allow the oil column to overflow from the opening when it reaches a certain height, and to prevent damage to the bracing structural column when the expansion pressure is too high. When the expansive soil swells after absorbing water, the expansive soil will push the retaining sheets to move toward the bracing column. At this moment, the piston compresses the oil in the cylinder as the pressure increases, and the oil column of the vertical oil pipe rises, and the pressure on the cylinder and the bracing structural column gradually increases. When the vertical pipe oil column reaches the height of the opening, the oil overflows from the opening, and the thrust acting on the bracing column remains constant, thereby protecting the bracing column from damage. When designed according to this scheme, it must be ensured that when the vertical pipe oil column overflows from the top opening, the pressure of the cylinder acting on the bracing structural column is less than the lateral thrust that the cantilever bracing structural column can withstand when it is bent to damage.

\section{Third, the one-way pressure relief valve scheme}

The one-way pressure relief valve scheme is basically the same as the oil column pressure scheme. The difference is that the one-way pressure relief valve replaces the vertical oil pipe of the oil column pressure scheme. The purpose is to make the entire retaining structure simpler and more compact. The one-way pressure relief valve scheme is shown in Figure 4. When the expansive soil swells after absorbing water, the expansive soil will push the retaining sheets to move toward the bracing column. At this moment, the piston compresses the oil in the cylinder with the increase of pressure, and the oil pressure in the cylinder and the pressure on the bracing structural column gradually Increase. When the oil pressure in the cylinder reaches the opening pressure threshold of the one-way relief valve, the relief valve is pushed open by the oil pressure in the cylinder, and the oil is ejected from the relief valve, and the thrust acting on the

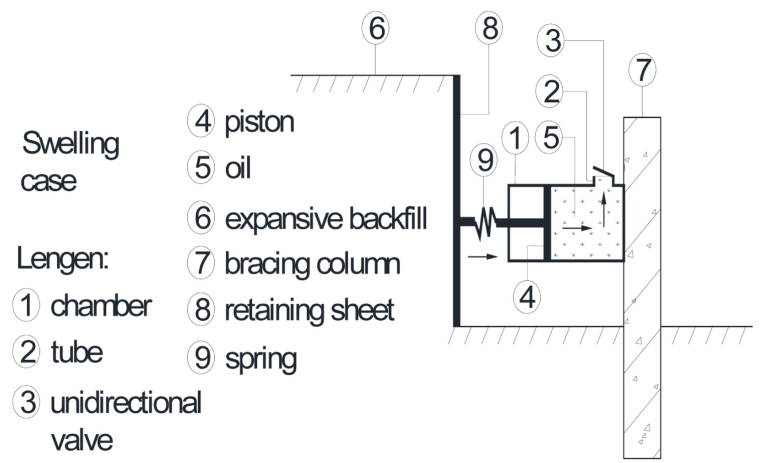

Figure 4. One-way pressure relief valve scheme. 
bracing column remains constant so as to protect the support column from damage. When designed according to this scheme, it must be ensured that when the one-way pressure relief valve is pushed open by the oil pressure in the cylinder, the pressure of the cylinder acting on the bracing structural column is less than the lateral thrust that the cantilever bracing structural column can withstand when it is bent to damage.

From the above analysis, it can be seen that these three schemes can protect the main bracing structural column from damage when the expansive soil swells with water. However, the first type of spring + buckling bar is a damage protection, that is, the primary component is protected from damage through the damage of the relatively secondary component. For this kind of scheme, once the buckling bar is buckled and damaged, it needs to be replaced manually. The replacement work is not simple and the workload is not small, so it is not recommended. For the second oil column pressure scheme, although no component is damaged when the supporting force reaches the maximum value, in order to ensure that the oil cylinder has sufficient supporting capacity, the vertical oil pipe needs to have a certain height, which not only leads to an increase in material consumption, but also the retaining structure becomes large and not compact enough. The third one-way pressure relief valve solution will not damage the structure when the supporting force reaches the maximum value, and the material consumption will be less than the second solution, and the structure looks more compact than the second solution. So the third scheme is the best option.

\subsection{Solutions for the Second Key Technical Issue}

For the second key technical problem, there are the following two solutions:

\section{First, the spring scheme}

In the above three schemes of Figure 1, Figure 3, and Figure 4, the scheme with springs is adopted. If the supporting force generated by the swelling of the expansive soil after absorbing water does not reach the maximum design value, that is, the buckling bar in the first scheme does not reach yield failure or the oil in the second and third schemes does not spray and overflow, the support structure in the spring can make the retaining structure well adapt to the swelling and shrinkage of the expansive soil when exposed to water. However, if the supporting force reaches the maximum design value and results in the failure of the buckling bar or the oil overflowing out of the cylinder, the simple spring scheme will not be able to adapt to the continuous cycle of water loss leading the shrinkage of the expansive soil and swelling when exposed to water, and it needs to explore for other improvements.

\section{Second, the slip-force device scheme with recycling oil cylinder}

\section{1) Concept of the slip-force device}

In the classical configuration depicted in Figure 5, the swelling pressure from the backfill is transmitted to the retaining wall directly [29] [30] [31] [32], which 


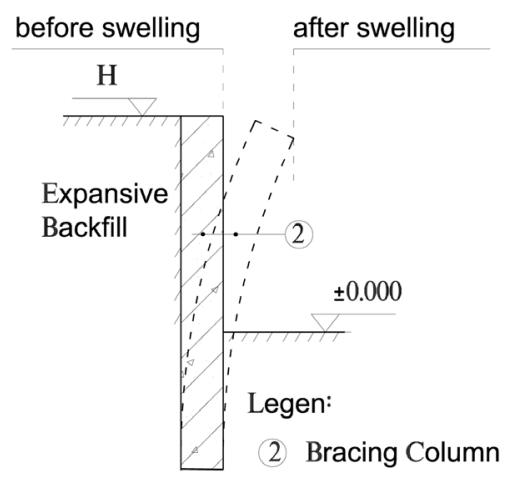

Figure 5. Traditional retaining scheme.

can cause the retaining structure to fail when the pressure increases as the soil expands. In the proposed retaining scheme shown in Figure 6, the retaining structure is separated into two parts:

a) The retaining sheet, which is in direct contact with the soil and is subjected to the lateral pressure directly from the expansive backfill but not embedded in the soil;

b) The bracing column, embedded in the soil, provides a constant support for the pressure transmitted by the slip-force device. The slip-force device is designed to allow swelling to happen but keeps the force on retaining structure constant. In the traditional design, the force applied to the retaining structure increases with swelling. The relationships between the pressure on the retaining structure (p) and the relative humidity $(\mathrm{h})$ for the traditional [33] and the proposed schemes are shown in Figure 7.

\section{2) Working process of the slip-force device}

The proposal slip-force device in Figure 8 is composed of a chamber, a piston, a relief valve, a unidirectional valve, conduct tubes, a pump and an open tank. In the initial state (before the device works or the piston moves), the pressure of the oil in the chamber has been set to the critical open pressure of the relief valve. When the backfill expansive soils swell, the swelling pressure will push the piston of the device and compress the oil in the chamber, and then the relief valve will open, but the unidirectional valve will close and the oil will be injected into the tank. When the backfill shrinks, the oil pressure in the chamber will decrease and the relief valve will close, by pumping (the pump not shown in Figure 8), the unidirectional valve will open and the oil in the tank will flow back into the chamber.

The slip-force device presented in this paper plays two important roles: first, it intentionally allows the expansive backfill to swell, providing a pressure release mechanism [1] [7] [20]; second, it keeps the force on the bracing column constant to prevent structural failure.

\section{Mathematical Model of the Proposed Slip-Force Device}

The system can be modeled as a linear single-degree-of-freedom system. Because 


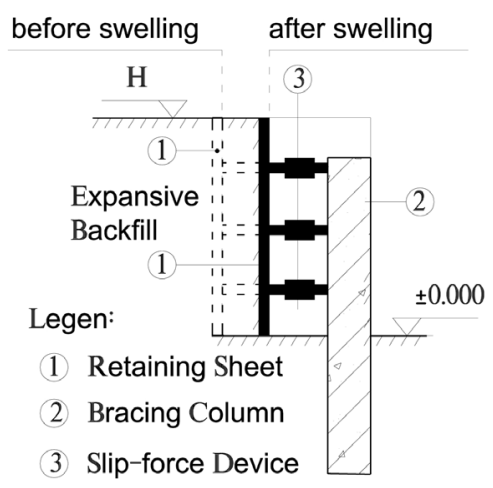

Figure 6. Proposal retaining scheme.

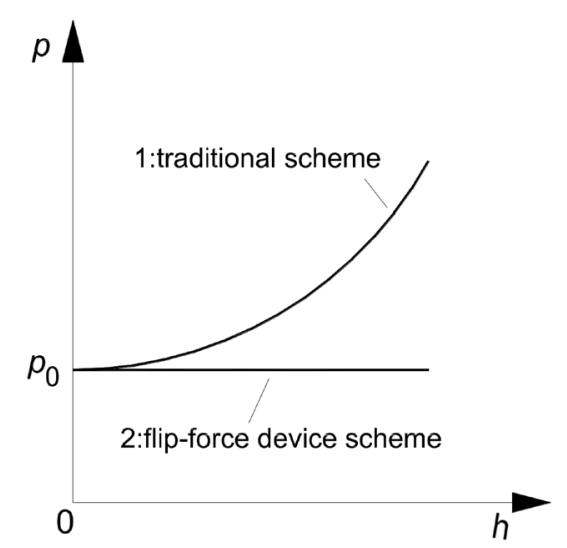

Figure 7. Relationship between pressure on retaining structures $(\mathrm{p})$ and relative humidity (h) with treatments in tradition and in this paper.

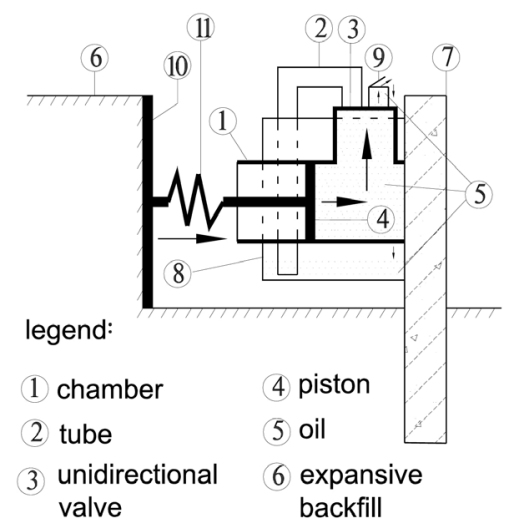

(a)

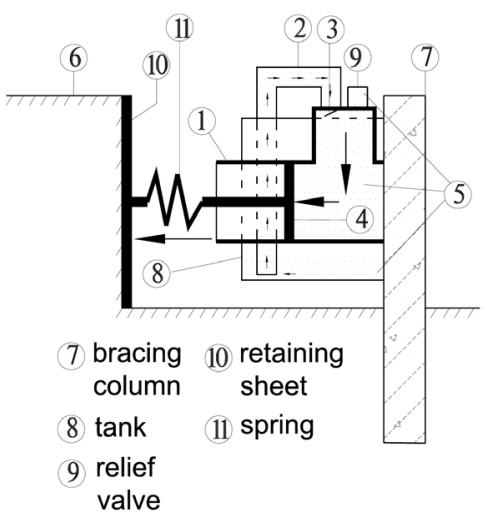

(b)

Figure 8. Working process of the proposal retaining scheme. (a) Swelling case; (b) Shrinkage case.

the movement of the soil is quasi static, the excitation can be simplified as a displacement input. The governing equation of the piston motion can be written as

$$
m \cdot \ddot{x}+D \cdot \dot{x}+k \cdot x=k \cdot u-\left(p_{c}+p\right) \cdot A
$$

in which $x$ denotes the displacement of piston relative to the initial equilibrium 
position, $\mathrm{m}$ the mass of the piston, $D$ the viscous damping coefficient of the fluid, $k$ the stiffness of the spring, $A$ the area of the piston and $u$ is the displacement of the soil. The total chamber pressure is contributed by the preset critical pressure $p_{c}$ of the relief valve and the pressure $p$ induced by volume changes, i.e. $(u-x) \cdot A$.

Define the bulk modulus $K$ as [34] [35]:

$$
K=-V \cdot \frac{\mathrm{d} p}{\mathrm{~d} V}
$$

where $V$ is the volume of the fluid in the chamber. By integrating Equation (2), the chamber pressure $p$ can be expressed as:

$$
p=-K \ln \left(1-\frac{A \cdot x}{V_{0}}\right)
$$

where $V_{0}$ is the initial fluid volume in chamber $(x=0)$. For small volume changes, a first approximation is sufficient, which gives:

$$
p=K \frac{A \cdot x}{V_{0}}
$$

Substituting Equation (4) into (1), the governing equation can be written as:

$$
m \cdot \ddot{x}+D \cdot \dot{x}+\left(k+K \cdot \frac{A^{2}}{V_{0}}\right) x=k \cdot u-p_{c} \cdot A
$$

\section{Numerical Results and Discussions}

\subsection{Model Parameters}

In this study, a single tie-back retaining wall [36] is considered as an example. The parameters of the wall are shown in Figure 9. The time history of the expansion reported in [37] is used in this study, which is shown in Figure 11 by the rectangular marks. In the proposed system, the open pressure of the valve is selected to be $354 \mathrm{kPa}$, the mass of the moving parts (piston etc.) is $m=5 \mathrm{~kg}$, the

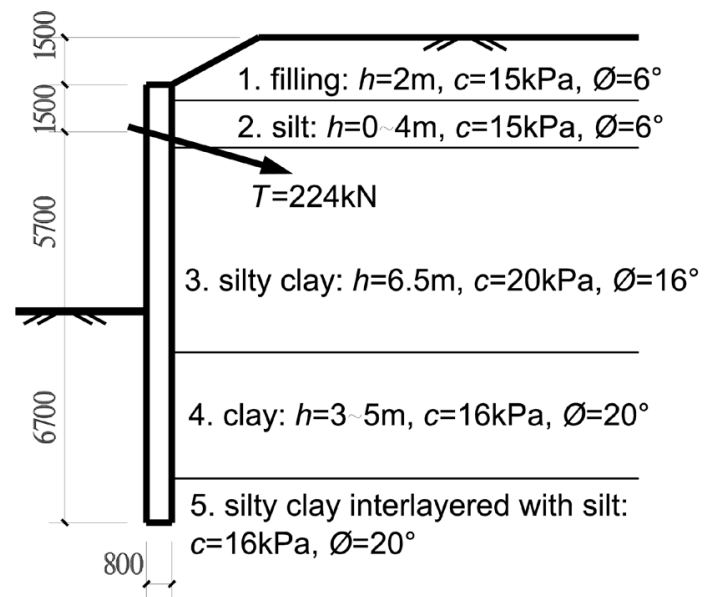

Figure 9. Sketch and parameters of retaining wall. 
diameter $d$ of the piston is $300 \mathrm{~mm}$, giving an area of $A=70,685.8 \mathrm{~mm}^{2}$, the initial volume of the chamber is $0.01 \mathrm{~m}^{3}$, the volumetric modulus is $K=2000 \mathrm{MPa}$, the viscous damping ratio of the fluid is $\xi=0.095$ and the spring constant $k$ is $4000 \mathrm{kN} / \mathrm{m}$

\subsection{Results and Discussions}

\subsubsection{Retaining Behavior of the System}

In the first case, the initial spring force was set to zero. Results are presented in Figure 10 and Figure 11. It can be seen from Figure 6 that it took about $60 \mathrm{~min}$. for the pressure to build up in the chamber and open the relief valve. Before the relief valve opened, the spring force increased with the swelling of the soil. After the relief valve was opened, the spring force kept constant, indicating a constant chamber pressure. Figure 11 shows the relationship between the piston displacement and soil swelling. It suggests that before the relief valve opened, the piston hardly moved even when the soil kept moving. After the critical pressure was reached and the relief valves opened, the piston began to move and it moved almost as fast as the soil.

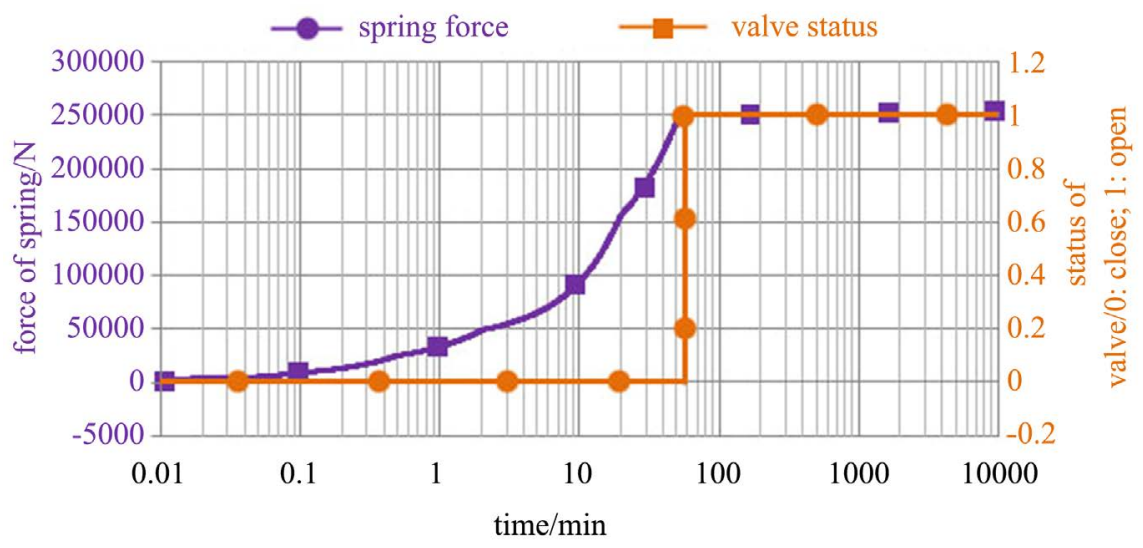

Figure 10. Spring force and valve status when $F_{\mathrm{i}}=0$.

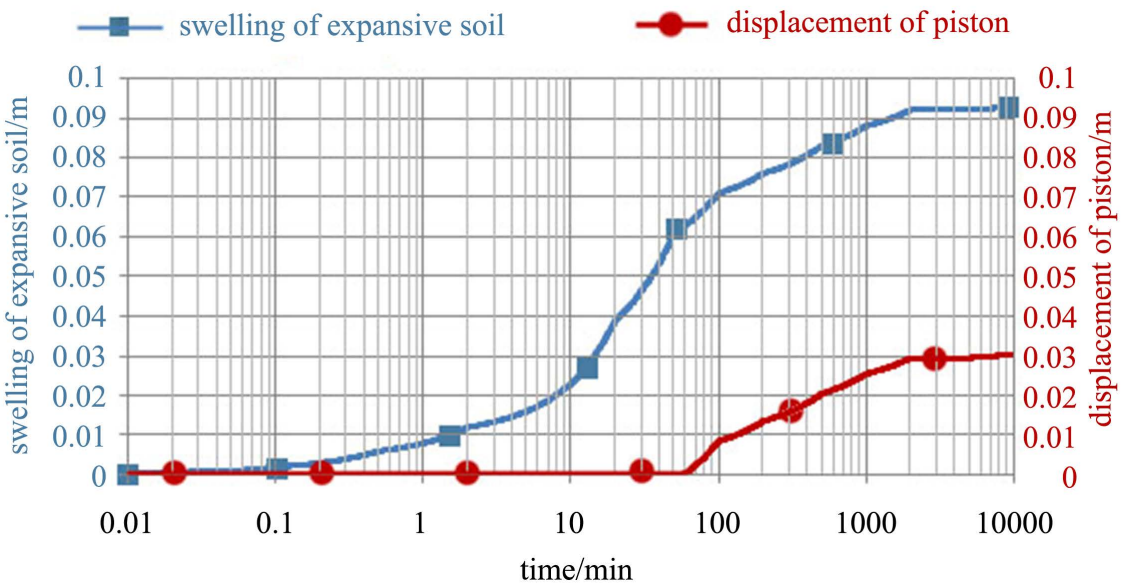

Figure 11. Soil swelling and piston displacement when $F_{1}=0$. 
When the initial spring force was set to the value corresponding to the critical open pressure of the relief valve, i.e. $250 \mathrm{kN}$ in this example, the relief valve kept open and the displacement of piston was found to be nearly the same as that of the swelling of expansive soil, indicating an almost constant spring force as confirmed by Figure 12. Thus, for the cases considered, after the relief valve opened, the spring force was kept at a constant level, which achieved the purpose of the proposed device.

\subsubsection{Lag of the System}

Hydraulic oils have viscosity feature and this feature may vary greatly from oil to oil [38] [39]. The viscosity of hydraulic oils may induce a lag of response in system. For the cases in this paper, the lag emerges when the damping ration $\xi=1$. When the damping ration $\xi=95$, the lag feature is very significant, as depicted from Figures 13-16. Figure 13 and Figure 14 also indicates that the viscosity of oils not only induce lag feature in the system, but also may bring slightly difference in maximum response of the system.

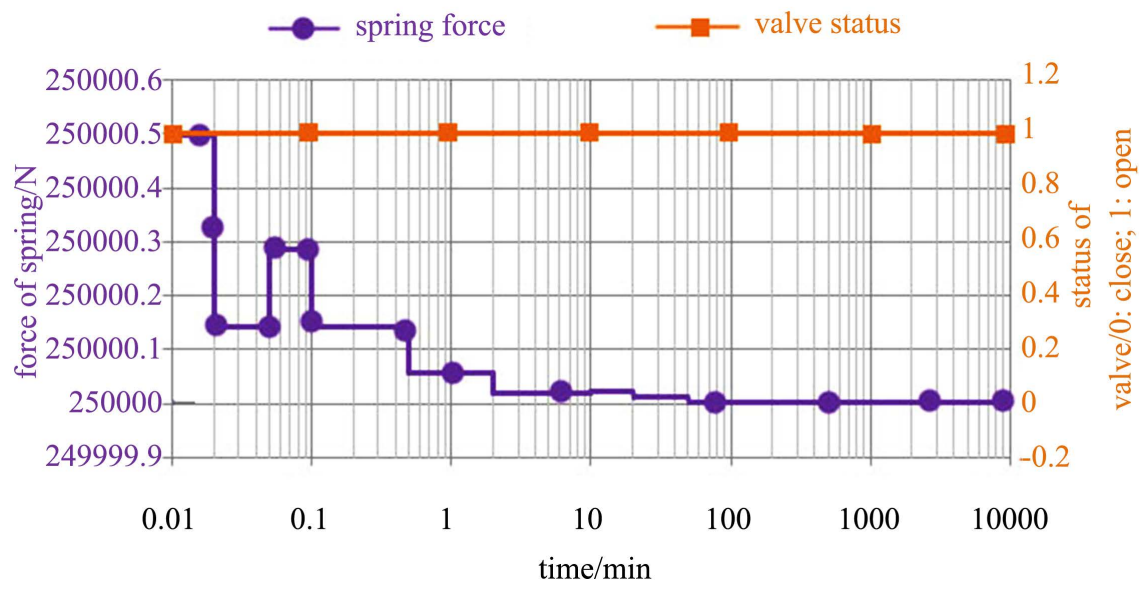

Figure 12. Time-history curves of spring force when $F_{1}=F_{0}$.

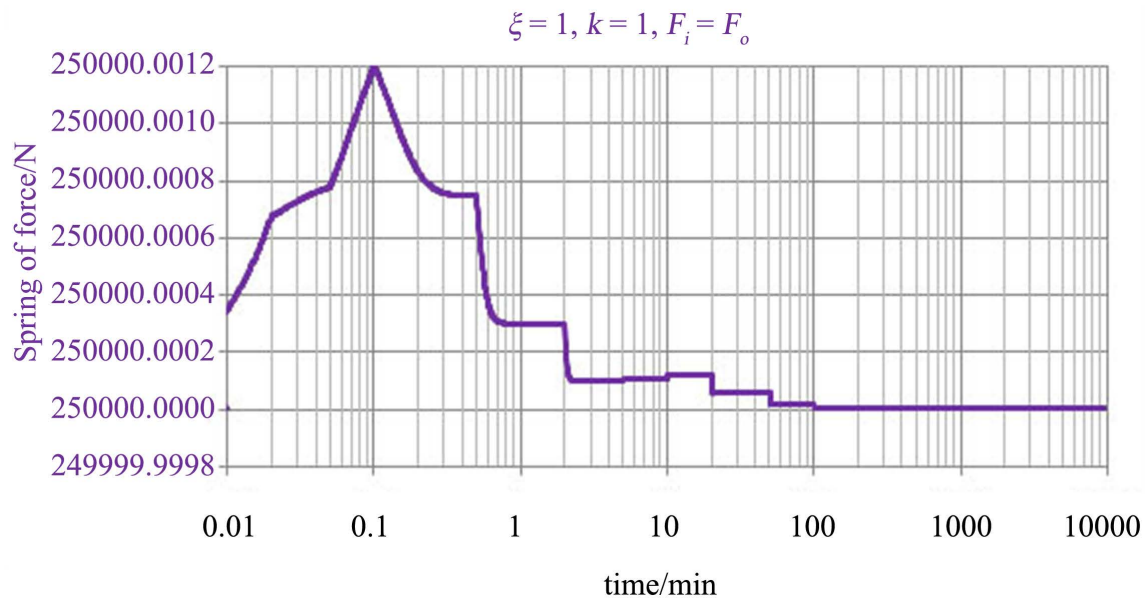

Figure 13. Response of spring force when $k=1 \mathrm{~N} / \mathrm{m}, \xi=1$ and $F_{1}=F_{0}$. 


$$
\xi=95, k=1, F_{i}=F_{o}
$$

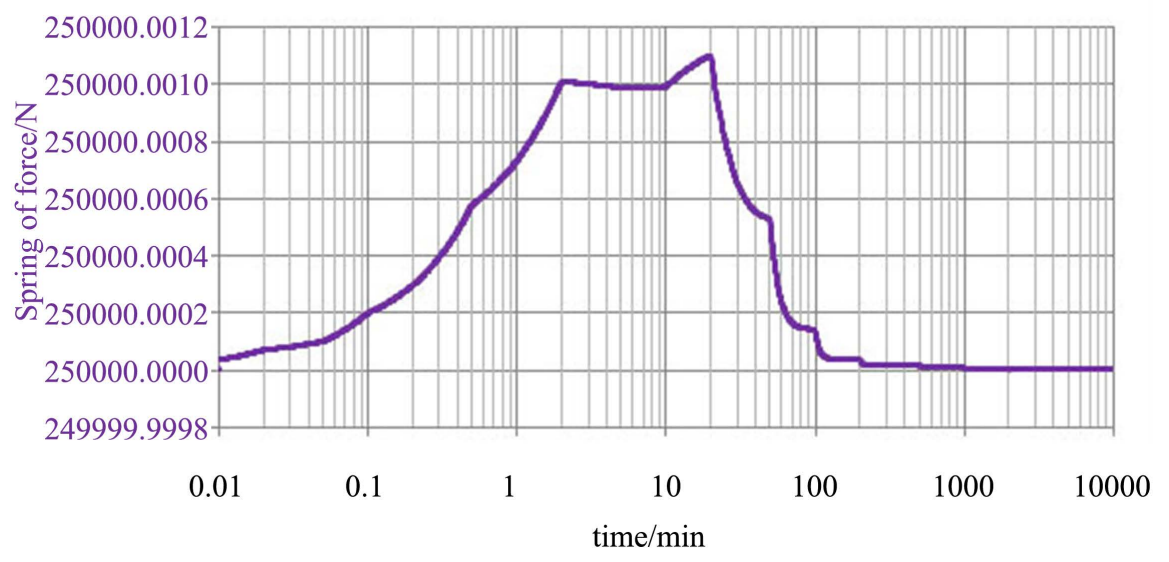

Figure 14. Response of spring force when $k=1 \mathrm{~N} / \mathrm{m}, \xi=95$ and $F_{\mathrm{i}}=F_{\mathrm{o}}$.

$$
\xi=1, k=1, F_{i}=0
$$

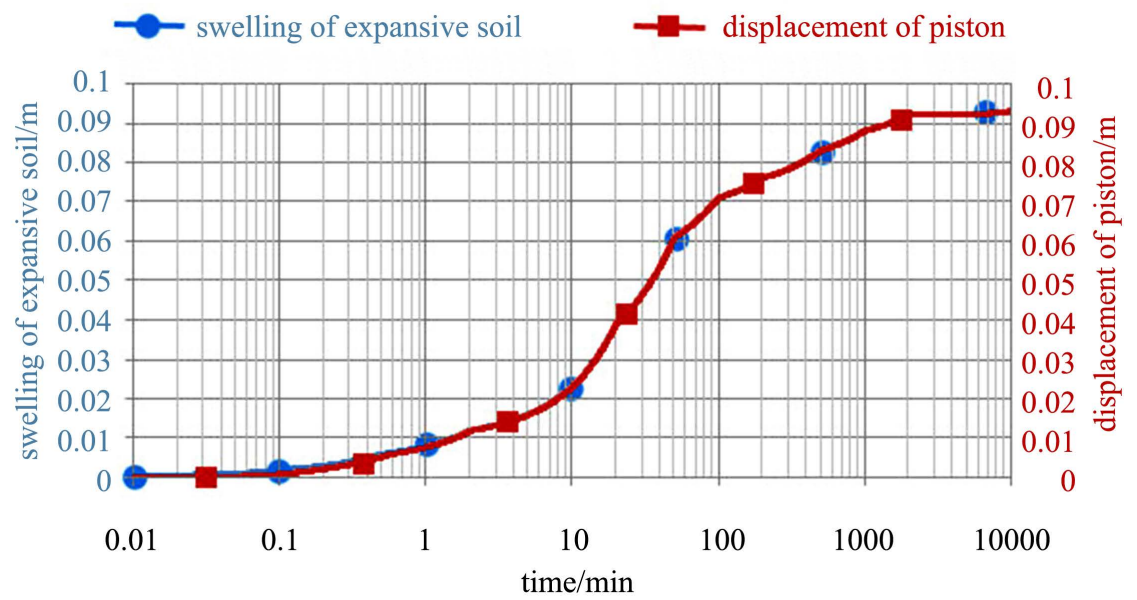

Figure 15. Soils swelling and piston displacement when $k=1 \mathrm{~N} / \mathrm{m}, \xi=1$ and $F_{1}=0$.

$$
\xi=95, k=1, F_{i}=0
$$
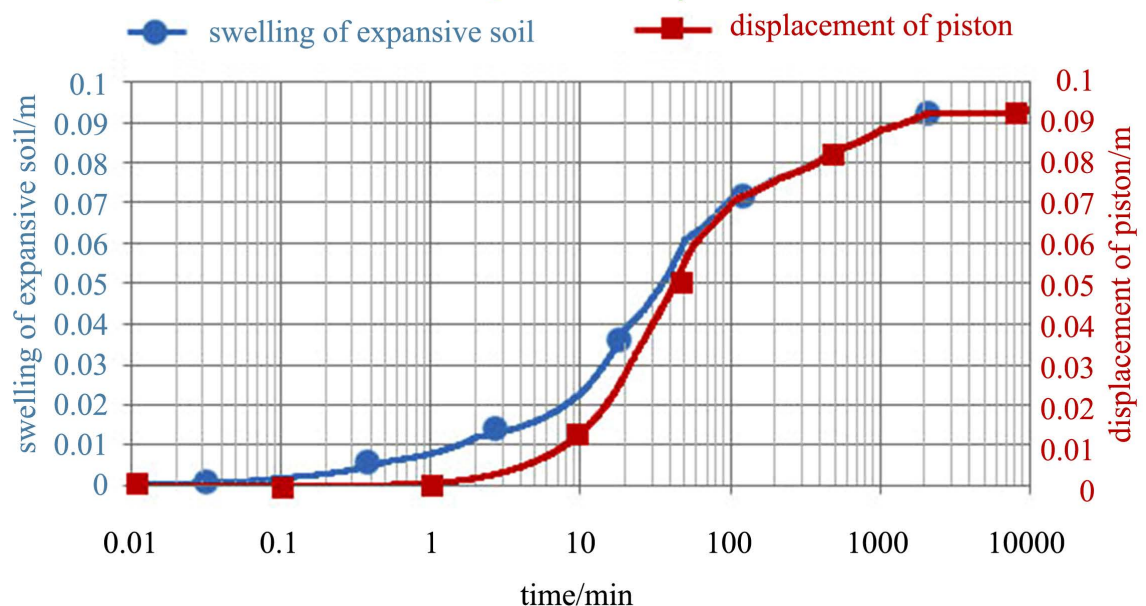

Figure 16. Soils swelling and piston displacement when $k=1 \mathrm{~N} / \mathrm{m}, \xi=95$ and $F_{1}=0$. 


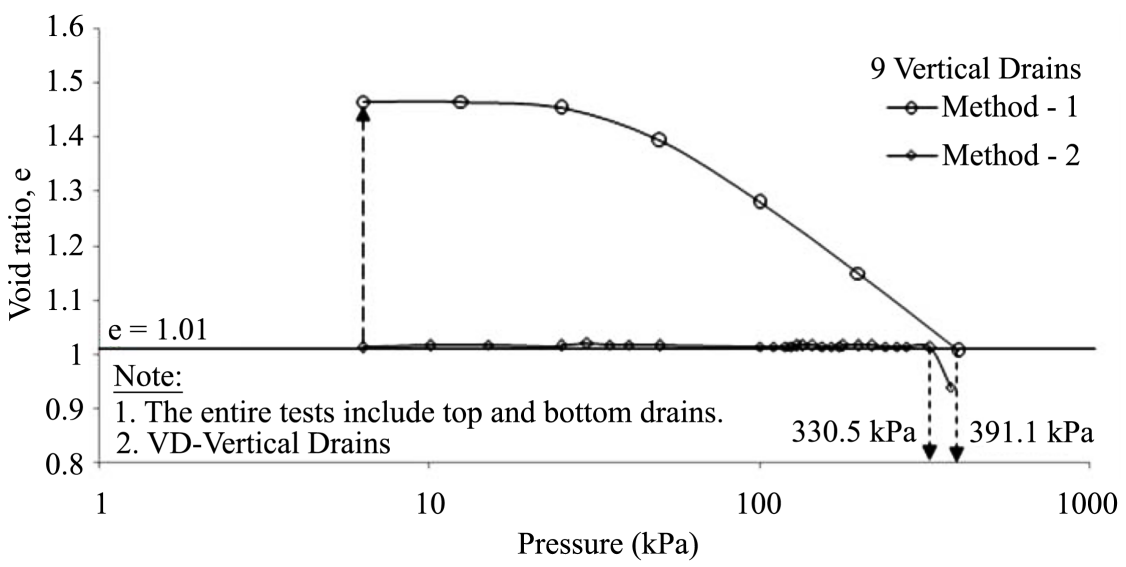

Figure 17. Log pressure versus void ratio (both Method 1 and Method 2) relationship for density $\left(=1.35 \mathrm{Mg} / \mathrm{m}^{3}\right)$ with nine vertical drains.

\subsubsection{Comparison of Results}

In the traditional retaining wall scheme, the expansive soil acts directly on the back of the retaining wall. When the expansive soil swells with water, the retaining wall prevents the expansion displacement of the expansive soil, and the expansion pressure of the retaining wall by the expansive soil will continue to increase as the water suction of the expansive soil increases. For the expansive soil with the characteristics of the expansion curve shown in Figure 11, it can be seen from the literature [37] that the expansion pressure on the retaining wall of the traditional scheme can increase from the initial less than $10 \mathrm{kPa}$ to the final $330.5 \mathrm{kPa}$, as shown in Figure 17 Method 2 (Zero-swell Method), if the retaining wall is not strong enough to withstand the swelling pressure of the expansive soil, the retaining wall will be distressed.

In the slip-force constant force device proposed in this paper, as long as the expansion force reaches the designed constant value, the pressure relief valve will open, and the bracing force acting on the bracing column will not increase, but keep constant, with the increase in the water suction of the expansive soil, as shown in Figure 10, Figures 12-14. As long as the constant force of the device is designed to not exceed the bearing capacity of the bracing column, the retaining structure of the new scheme will not be distressed.

\section{Conclusions}

A flip-force device has been proposed to protect retaining structures from being distressed by the swell of expansive soils. The device, located between expansive soils and retaining wall, introducing the principle of relief valve, can accommodate the swelling displacement of expansive soils but keep constant the push force acting on retaining structures by expansive soils.

By analyzing the dynamic equilibrium of the piston in the hydraulic system, a theoretical model has been established for this flip-force device. In this study, a simple linear SDOF system was considered. Numerical simulations were performed for a real retaining structure in expansive soils. 
Results confirmed that the flip-force device can maintain a constant swelling force acting on retaining structures by expansive soils, thereby protecting the retaining structures in expansive soils. Results also suggested that the viscocity of hydraulic oil not only can induce a lagged system response, but also may slightly change the maximum response of the system.

Smart technology can be considered to be introduced into this retaining system in future work. For example, smart monitoring and smart controlling technology can be applied to this retaining structure so that the structure can make proper reaction automatically according to the monitoring data.

\section{Conflicts of Interest}

The author declares no conflicts of interest regarding the publication of this paper.

\section{References}

[1] Jie, L., Cameron, D.A. and Gang, R. (2014) Case Study and Back Analysis of a Residential Building Damaged by Expansive Soils. Computers \& Geotechnics, 56, 89-99. https://doi.org/10.1016/j.compgeo.2013.11.005

[2] Snethen, D.R. (1975) A Review of Engineering Experiences with Expansive Soils in Highway Subgrades: Interim Report. Federal Highway Administration, Washington DC.

[3] Okagbue, C.O. (1990) Expansive Soils in Engineering Construction: A Review of Practices. Journal of Mining and Geology, 2, 123-129.

[4] Cokca, E. (1999) Effect of Fly Ash on Swell Pressure of an Expansive Soil. Electronic Journal of Geotechnical Engineering, 4, 14.

[5] Fu, H. and Chen, F.H. (1975) Foundations on Expansive Soils.

[6] Yitagesu, F.A., van der Meer, F., van der Werff, H. and Zigterman, W. (2009) Quantifying Engineering Parameters of Expansive Soils from Their Reflectance Spectra. Engineering Geology, 105, 151-160. https://doi.org/10.1016/j.enggeo.2009.01.004

[7] Aytekin, M. (1992) Finite Element Modeling of Lateral Swelling Pressure Distribution behind Earth Retaining Structures. Doctoral Dissertation, Texas Tech University, Lubbock.

[8] Fourie, A.B. (1989) Laboratory Evaluation of Lateral Swelling Pressure. Journal of Geotechnical Engineering, 115, 1481-1486. https://doi.org/10.1061/(ASCE)0733-9410(1989)115:10(1481)

[9] Coulomb, C.A. (1776) Essai sur une application des règles de maximis et Minimis à quelques problèmes de statique, relatifs à l'architecture, Mémories de Mathématique et de Physique présentés à I’Académe Royale des Sciences, Paris.

[10] Mohamed, O.Z., Taha, Y.K., El-Aziz, A. and El-Sharif, M. (2014) Experimental Study on the Effect of Lateral Swelling Pressure of Expansive Soil on Retaining Structure. Journal of Engineering Sciences, 42, 84-92. https://doi.org/10.21608/jesaun.2014.114283

[11] Aytekin, M. (1997) Numerical Modeling of EPS Geofoam Used with Swelling Soil. Geotextiles and Geomembranes, 15, 133-146. https://doi.org/10.1016/S0266-1144(97)00010-1 
[12] Symons, I.F., Clayton, C.R.I. and Darley, P. (1989) Earth Pressures against an Experimental Retaining Wall Backfilled with Heavy Clays. Research Report No. 192, Transport and Road Research Lab., Crowthorne.

[13] Viswanadham, B.V.S., Phanikumar, B.R. and Mukherjee, R.V. (2009) Swelling Behaviour of a Geofiber-Reinforced Expansive Soil. Geotextiles and Geomembranes, 27, 73-76. https://doi.org/10.1016/j.geotexmem.2008.06.002

[14] Ertugrul, O.L. and Trandafir, A.C. (2013) Lateral Earth Pressures on Flexible Cantilever Retaining Walls with Deformable Geofoam Inclusions. Engineering Geology, 158, 23-33. https://doi.org/10.1016/j.enggeo.2013.03.001

[15] Fabian, K.J. and Fourie, A.B. (1988) Clay-Geotextile Interaction in Large Retaining Wall Models. Geotextiles and Geomembranes, 7, 179-201. https://doi.org/10.1016/0266-1144(88)90008-8

[16] Skinner, G.D. and Rowe, R.K. (2005) Design and Behaviour of a Geosynthetic Reinforced Retaining Wall and Bridge Abutment on a Yielding Foundation. Geotextiles and Geomembranes, 23, 234-260. https://doi.org/10.1016/j.geotexmem.2004.10.001

[17] Wankhade, S.R., Rajurkar, V.J. and Dahale, P. (2014) Improvement of Swelling-Shrinkage Behaviour of Expansive Soil Using EPS Beads. International Journal of Applied Engineering Research, 9, 223-228.

[18] Petry, T.M. and Little, D.N. (2002) Review of Stabilization of Clays and Expansive Soils in Pavements and Lightly Loaded Structures-History, Practice, and Future. Journal of Materials in Civil Engineering, 14, 447-460. https://doi.org/10.1061/(ASCE)0899-1561(2002)14:6(447)

[19] Ramaji, A.E. (2012) A Review on the Soil Stabilization Using Low-Cost Methods. Journal of Applied Sciences Research, 8, 2193-2196.

[20] Xu, J.L. (2007) Study on Screening of Expansive Soil-Improving Strain and Condition Selection. Guangxi University, Nanning.

[21] Ikizler, S.B., Aytekin, M. and Nas, E. (2008) Laboratory Study of Expanded Polystyrene (EPS) Geofoam Used with Expansive Soils. Geotextiles and Geomembranes, 26, 189-195. https://doi.org/10.1016/j.geotexmem.2007.05.005

[22] Casciati, F., Rodellar, J. and Yildirim, U. (2012) Active and Semi-Active Control of Structures-Theory and Applications: A Review of Recent Advances. Journal of Intelligent Material Systems and Structures, 23, 1181-1195. https://doi.org/10.1177/1045389X12445029

[23] Yao, J.T. (1972) Concept of Structural Control. Journal of the Structural Division, 98, 1567-1574. https://doi.org/10.1061/JSDEAG.0003280

[24] Korkmaz, S. (2011) A Review of Active Structural Control: Challenges for Engineering Informatics. Computers \& Structures, 89, 2113-2132. https://doi.org/10.1016/j.compstruc.2011.07.010

[25] Takamatsu, T., Tamai, H., Yamanishi, T. and Matsuo, A. (2005) Models of Restoring Force Characteristics for Exposed Column Base with Wedge Device. Third International Symposium on Steel Structure, Seoul, 11-15 March, 2005 ,497-504.

[26] Takamatsu, T., Tamai, H., Yamanishi, T., et al. (2005) A Study on Self-Centering Performance of Non-Slip-Type Exposed Column Base. Journal of Constructional Steel, 13, 193-196.

[27] Takamatsu, T., Tamai, H. and Yamanishi, T. (2005) Models of Restoring Force Characteristics of Non-Slip-Type Exposed Column Bases. Journal of Constructional Steel, 13, 51-56. 
[28] Takamatsu, T., Tamai, H., Yamanishi, T., et al. (2005) Rehabilitation Technique of Exposed-Type Column Bases in an Existing Gymnasium by Use of Wedge Device. IABSE Symposium 2005, Lisbon, 14-17 September 2005, 166-174. https://doi.org/10.2749/222137805796270342

[29] Hong, G.T. (2008) Earth Pressures and Deformations in Civil Infrastructure in Expansive Soils. Texas A\&M University, College Station.

[30] Sahin, H. (2011) Characterization of Expansive Soil for Retaining Wall Design. Texas A \& M University, College Station.

[31] Mohamed, O.Z., Taha, Y.K. and El-Aziz, E.S.M.A. (2014) Field Study of the Distribution of Lateral Swelling Pressure of Expansive Soil on Retaining Structure. Journal of Engineering Sciences, 42, 289-302.

https://doi.org/10.21608/jesaun.2014.114713

[32] Headquarters, Department of the Army (1983) Foundations in Expansive Soils (TM 5-818-7). Headquarters, Department of the Army, Washington DC.

[33] Wen, S.S. (2017) Experimental Study on the Expansive Force in the Expansive Soil in Ningming County of Guangxi. Guilin University of Technology, Guilin.

[34] Bansal, R.K. (2014) A TextBook of Fluid Mechanics and Hydraulic Machines: (In S.I. Units, Revised Ninth Edition). Laxmi Publications, Telangana.

[35] MSC.Software Corporation (2010) EASY5 2010, Quick Start Tutorial for Use with Windows. MSC.Software Corporation, Newport Beach.

[36] Xu, Y.Q. (2001) Study of Optimum-Design Theory and Dynamic Displacement-Controlling of Deep Excavation. Wuhan University of Technology, Wuhan.

[37] Nagaraj, H.B., Munnas, M.M. and Sridharan, A. (2009) Critical Evaluation of Determining Swelling Pressure by Swell-Load Method and Constant Volume Method. Geotechnical Testing Journal, 32, 305-314. https://doi.org/10.1520/GT]102051

[38] Hou, Y., Shi, B., Xiao, C., Wang, H. and Guo, P. (2009) Dynamic Characteristics of Hydraulic Pipelines of Steering System of Articulated Vehicles. Transactions of the Chinese Society of Agricultural Engineering, 25, 112-116.

[39] Huang, C. and Tan, J. (2009) Response Characteristic of Fluid Pressure in Operating Cylinder for 300MN Die Forging Hydraulic Press. Machine Tool \& Hydraulics, 27, 88-91. https://doi.org/10.1109/ICMTMA.2009.619 